\section{A new method for the quantification of Melamine in milk by Absorption Diode Array Thin-Layer
Chromatography}

Prof. Dr. rer. nat. Bernd Spangenberg

Fakultät Maschinenbau und Verfahrenstechnik $(M+V)$

Studiendekan Verfahrenstechnik

Badstraße 24

77652 Offenburg

Tel. 0781 205-101

E-Mail: Spangenberg@fh-offenburg.de
1955: Geboren in Remscheid

Studium der Chemie und Philosophie an der Universität Marburg 1983: Diplom in Chemie, 1987 Promotion über neue Reaktionen von Sulfenen am Pharmazeutischen Institut der Universität Marburg 1988: Eintritt in die E. Scheurich Pharmwerk GmbH als Laborleiter, Leiter der Abteilung analytische Forschung und Entwicklung, stellvertretender Kontrollleiter 1990: Wechsel zur EBULON AG,

Basel als Leiter der Entwicklungsanalytik

1991: Professor an der Hochschule Offenburg, Leiter des Labors für Analytik und Umweltanalytik

Seit 2007: Editor-in-Chief von Journal of Planar Chromatography

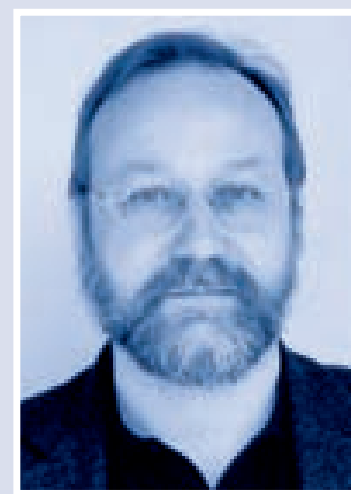

Lehrgebiete: Analytik, Umweltanalytik, Abfall- und Recyclingtechnik Mitglied des Instituts für Angewandte Forschung (IAF) der Hochschule Offenburg Forschungsgebiete: Chemometrie, Trenntechniken, Dünnschichtchromatographie
3.5 A new method for the quantification of Melamine in milk by Absorption Diode Array Thin-Layer Chromatography

Prof. Dr. rer. nat Bernd Spangenberg Dipl.-Ing. (FH) Melanie Broszat Regina Brämer

\section{Introduction}

Melamine (1,3,5-triazine-2,4,6-triamine or cyanuramide, $\mathrm{C}_{3} \mathrm{H}_{6} \mathrm{~N}_{6}$ ) is a trimer of cyanamide, with a 1,3,5-triazine skeleton (Figure 3.5-1). The molecule contains $66 \%$ nitrogen by mass and, if mixed with resins, has fire retardant properties due to its release of nitrogen gas when burned or charred. The word melamine (from German) is a combination of the word melam (which is a distillation derivative of ammonium thiocyanate) and amine [1]. Melamine is also a metabolite of cyromazine, an insecticide in which the proton of an $\mathrm{NH}_{2}$-group is substituted by a cyclopropyl group.

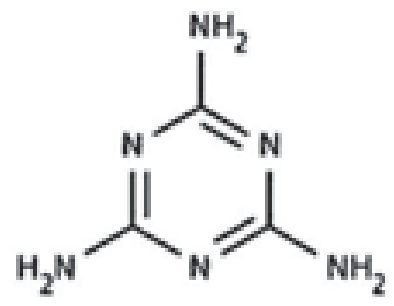

Fig. 3.5-1: shows the formula of melamine

In September 2008, several companies were implicated in a scandal involving milk and infant formula which had been adulterated with melamine, leading to kidney stones and other renal failure, especially among young children [2].

Melamine was illegally added to food products in order to increase the apparent protein content. Standard tests such as the Kjeldahl test estimate protein levels by measuring the nitrogen content. Because of melamine's high nitrogen content, it can cause the protein content of food to appear higher than the true value.

For the determination of melamine in milk [3] and food [4] High Performance Liquid Chromatography (HPLC) in combination with mass spectrometry is used. A Thin Layer Chromatography (TLC) method for melamine quantification is not described. The purpose of our publication is to develop a fast and inexpensive method that will work reliably. It should be used for screening and quantification of melamine in milk and milk products.

\section{Experimentals}

Milk was diluted with the same amount of water and applied band-wise (7 mm) on a TLC K60 silica gel 60 foil (No. 1.05554.0001 from Merck, Darmstadt, Germany) in the amount of $1 \mu \mathrm{L}$. A Desaga AS 30 sample applicator (Desaga, Heidelberg, Germany) was used with a spraying velocity of $80 \mathrm{sec} / \mu \mathrm{L}$. The plate was developed in a vertical glass chamber (without chamber saturation) to a distance of $55 \mathrm{~mm}$ with the solvent mixture of 2-propanole, $\mathrm{CH}_{2} \mathrm{Cl}_{2}$, water $(3+1+1, \mathrm{~V} / \mathrm{V})$. The separation took 35 minutes. The solvents were purchased from Roth, Karlsruhe, Germany.
The plate was dried in a gentle stream of air for 5 minutes and placed in a chlorine containing chamber for 5 minutes. Chlorine was produced from $10 \mathrm{~mL} \mathrm{KM}$ nO4-solution $\left(3 \mathrm{~g} \mathrm{KMnO}_{4}\right.$ in $100 \mathrm{~mL}$ of water) and $10 \mathrm{~mL} \mathrm{HCl}(25 \mathrm{~mL} 32 \% \mathrm{HCl}$ dissolved in $50 \mathrm{~mL}$ of water). $\mathrm{HCl}$ and $\mathrm{KMnO}_{4}$ were purchased from Merck, Darmstadt, Germany. Five minutes after mixing the chamber was filled with chlorine and the TLC-plate could be placed.

Two staining reagents, Wuster's blue and starch/iodine reagents were found to show sufficient sensitivity. $500 \mathrm{mg}$ of Wuster's blue reagent $\left(\mathrm{N}, \mathrm{N}, \mathrm{N}^{\prime}, \mathrm{N}^{\prime}\right.$-tetramethyl-1,4-phenyldiammonium chloride from Alfa Aesar, Karlsruhe, Germany), was dissolved in $100 \mathrm{~mL}$ of acetone and is stable for 8 hours. To produce the starch/iodine reagent $250 \mathrm{mg}$ of potassium iodide (from Riedel-de Haën, Seelze, Germany) was dissolved in $25 \mathrm{~mL}$ of water. $750 \mathrm{mg}$ starch (according to Zulkowsky from Merck, Darmstadt, Germany) was dissolved in $25 \mathrm{~mL}$ of water. Both solutions were mixed and diluted with $30 \mathrm{~mL}$ of ethanol (from Roth, Karlsruhe, Germany). The mixture was stable for one day. For spraying $800 \mathrm{mg} \mathrm{KI}$ and $800 \mathrm{mg}$ starch were dissolved in $25 \mathrm{~mL}$ of water, respectively. Both solutions were mixed and diluted with $10 \mathrm{~mL}$ of ethanol.

The chlorinated TLC-plate was dipped for $2 \mathrm{sec}$ in Wuster's blue reagent, forming deep blue zones on a light blue background. Dipped plates were scanned by 
use of a diode-array scanner (TIDAS TLC 2010 system J\&M company, Aalen, Germany) [5]. Scanning should be done within 6 hours after dipping in the wavelength range from 550 to $615 \mathrm{~nm}$. Bluebrown zones are formed on a light dark background, if the chlorinated plate is dipped for $1 \mathrm{sec}$ in starch/iodine reagent. The colours remain stable for days. The zones were scanned in the wavelength range from 490 to $610 \mathrm{~nm}$. Scanning of a single track was done for 550 spectra in the wavelength range from 200 to $1000 \mathrm{~nm}$ in 55 seconds.

\section{Results and Discussion}

Figure 3.5-2 shows a starch/iodine stained plate. Pure milk was applied on track 1 . Track 2 to 8 show milk samples, spiked with different amounts of melamine. The milk sample on track 2 was spiked with $160 \mathrm{ng}$ and the sample on track 8 with 4 ng melamine. $1 \mu \mathrm{L}$ of water diluted milk $(1+1, \mathrm{~V} / \mathrm{V})$ was applied on each track.

In Figure 3.5-3 and 3.5-4, eight milk samples were applied on the TLC-plate. On each track 80 ng of melamine were separated. The plate in Figure 3.5-3 was stained using the starch/iodine reagent. The plate in Figure 3.5-4 was stained using Wuster's blue reagent.

The amount of $80 \mathrm{ng}$ melamine in $0.5 \mu \mathrm{L}$ milk is $160 \mathrm{ng}$ in $1 \mu \mathrm{L}$ pure milk, or 160 mg melamine in $1 \mathrm{~L}$ of milk. The statistically defined quantification limit is 25 ng or $50 \mathrm{mg}$ melamine in $1 \mathrm{~L}$ of pure milk.

For quantification purposes the light absorption (A) was measured directly on plate, using equation (1).

$$
A(\lambda, k=1)=\left(\frac{J_{0}}{J}-1\right)
$$

In this equation $J_{0}$ stands for the reflected light intensity of a clean TLC-plate and J refers to the reflected light of the sample. A single track of the TLC-plate was scanned, measuring 550 spectra in the wavelength range from 200 to $1000 \mathrm{~nm}$. A separation distance of $1 \mathrm{~cm}$ was scanned in 100 spectra. The spectral intensity was calculated using equation (1). The intensity distribution of a single track drawn with the separation distance is called "densitogram".
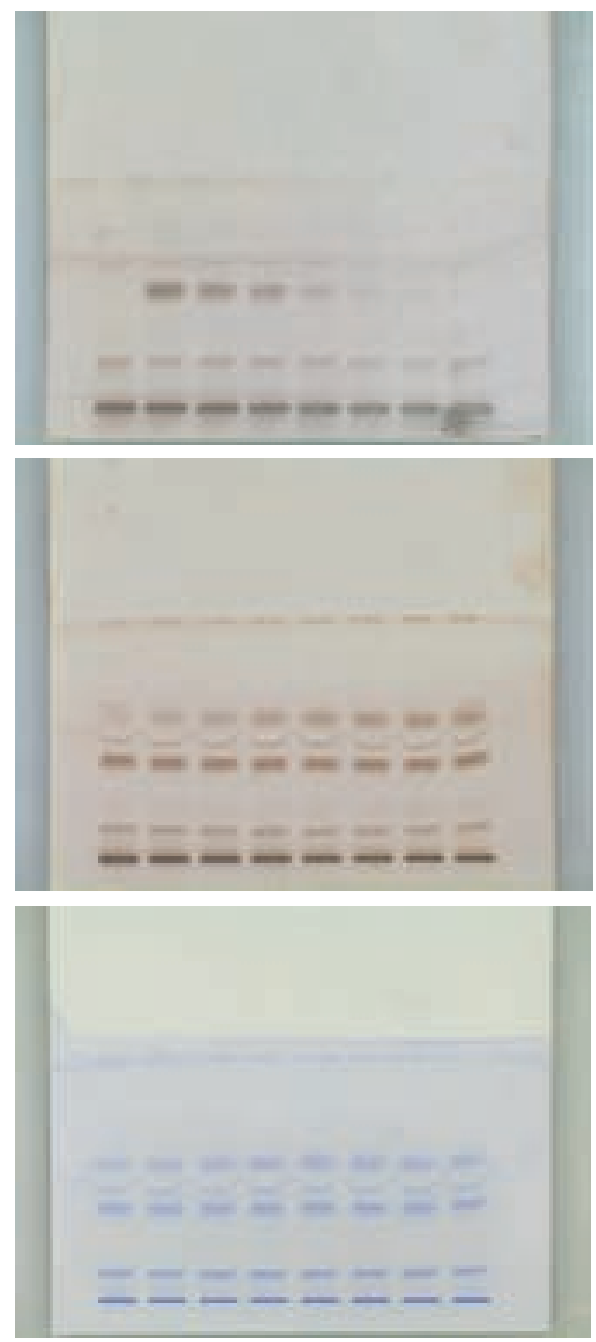

Fig. 3.5-2: shows a plate stained with starch/iodine reagent. On the first track a milk sample without melamine is shown

Fig. 3.5-3: shows eight melamine spiked milk samples (each with $1 \mu$ L applied), stained with starch/iodine reagent spiked milk samples (each Wuster's blue reagent
Fig. 3.5-4: shows eight melamine with $1 \mu$ L applied), stained with

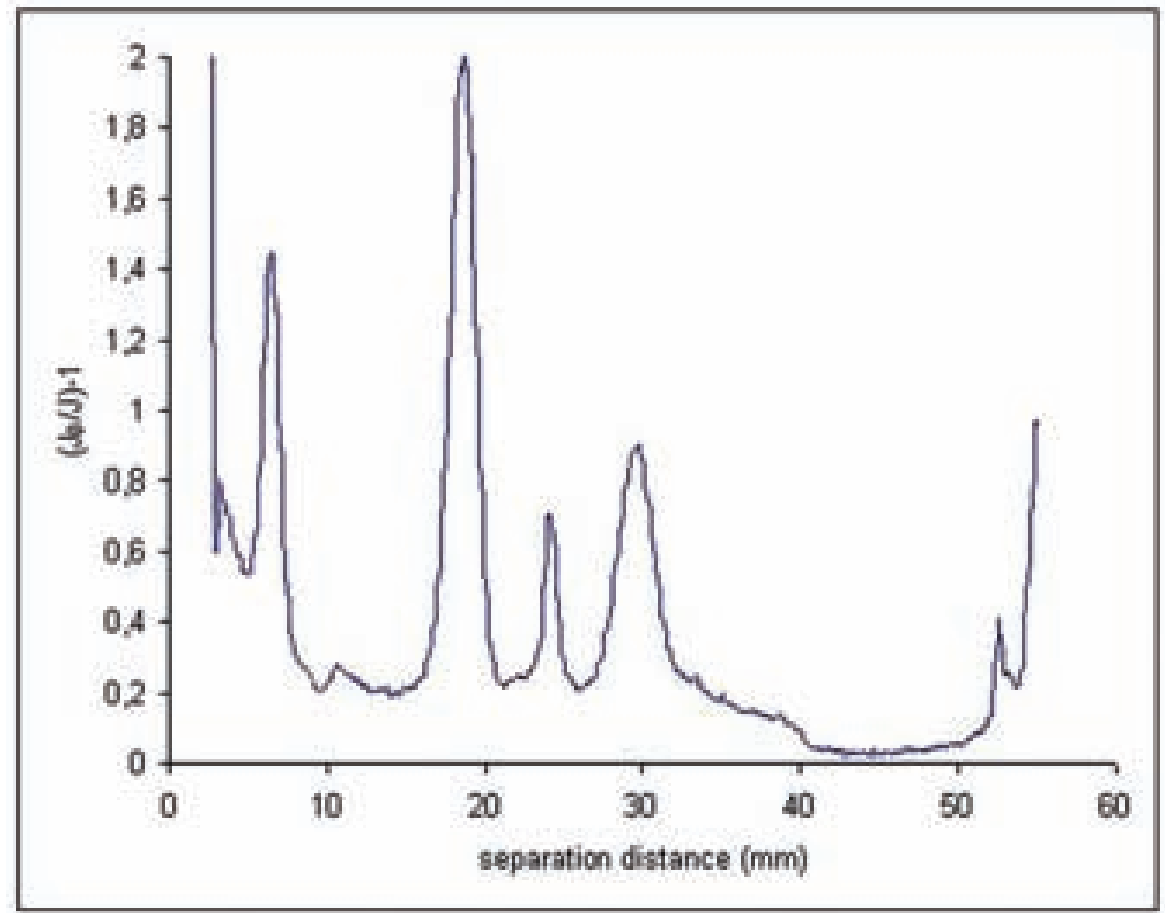

Fig. 3.5-5: shows the densitogram of melamine spiked milk sample. The melamine signal (containing $80 \mathrm{ng}$ ) can be seen at $18.7 \mathrm{~mm}$ separation distance. The plate was dipped in Wuster's blue reagent and evaluated in the wavelength range from 550 to $615 \mathrm{~nm}$ 
Figure 3.5-5 shows the absorption densitogram of a Wuster's blue stained milk sample, which contains $80 \mu \mathrm{g} / \mathrm{mL}$ of melamine. The melamine peak appears at $18.7 \mathrm{~mm}$ separation distance and shows an Rf-value of $R f=0.30$. A huge signal at the point of application can be seen at $3 \mathrm{~mm}$ separation distance. The main milk content did not move with the mobile phase and remained at the point of application. The front signal can be seen at $55 \mathrm{~mm}$ separation distance. The milk signals were scanned below 10 $\mathrm{mm}$ and above $21 \mathrm{~mm}$ separation distance.

Accuracy was tested using a spiked milk sample diluted with water to the desired concentrations to compare them with the same spiked milk sample diluted with milk. The same sensitivity of the calibration curve was calculated (either dissolved with milk or water) for both staining methods. This indicates that milk does not interfere with the melamine zone.

The calibration plot Figure 3.5-6 shows linearity for both staining methods in the range from $4 \mathrm{ng}$ to $160 \mathrm{ng}$ melamine, evaluated using the absorption formula $[5,6]$. The statistically evaluated limit of detection (LOD) for both methods is $15 \mathrm{ng}$ (30 mg melamine/L milk) [7]. The statistically evaluated limit of quantification (LOQ) for both methods is $25 \mathrm{ng}$ (50 mg melamine/L milk) $<$ [7]. The standard deviation of spiked milk samples over all measurement steps with a melamine level of $20 \mathrm{ng} /$ zone for Wuster's reagent is $8.9 \%$ and for the starch/iodine reagent $7.1 \%$.

Eight samples were applied in parallel on a 10 by $10 \mathrm{~cm}$ TLC-plate. The total measurement time for 8 samples was 65 minutes, including all sample pre-treatment steps. The method is suitable for melamine screening in milk and milk powder down to $50 \mathrm{mg}$ melamine/L milk at a low cost level.

\section{References}

[1] "Melamine. The American Heritage Dictionary of the English Language: Fourth Edition 2000". Retrieved on 2008-09-28

[2] Jane Macartney (22 September 2008). China baby milk scandal spreads as sick toll rises to $13,000^{\prime \prime}$, The Times

[3] Ishiwata, H.; Inoue, T.; Yamazaki, T.; Yoshihira, K. "Liquid-chromatographic determination of melamine in beverages", J. Assoc. Off. Anal. Chem. (1987) 70, 457-460

[4] J.V. Sancho, M. Ibanez, S. Grimalt, O.J. Pozo, F. Hernandez, „Residue determination of cyromazine and its metabolite melamine in chard samples by ion-pair liquid chroma- tography coupled to electrospray tandem mass spectrometry", Analytica Chimica Acta (2005) 530, 237 243 (2005)

[5] Bleichert, M.; Eckhardt, H.-S.; Klein, K.-F.; Spangenberg, B., "A simple and reliable method for quantification of glucosamine in nutritional supplements ", J. Planar Chromatogr. TLC (2008) 21, 55-59

[6] B. Spangenberg, „Does the Kubelka-Munk Theory describe TLC evaluations correctly?" J. Planar Chromatogr. (2006) 19, 332-341

[7] Funk, W., Dammann, V., Donnevert, G., Quality Assurance in Analytical Chemistry, 2. ed., Wiley-VCH 2007, $34-36$, Weinheim Germany

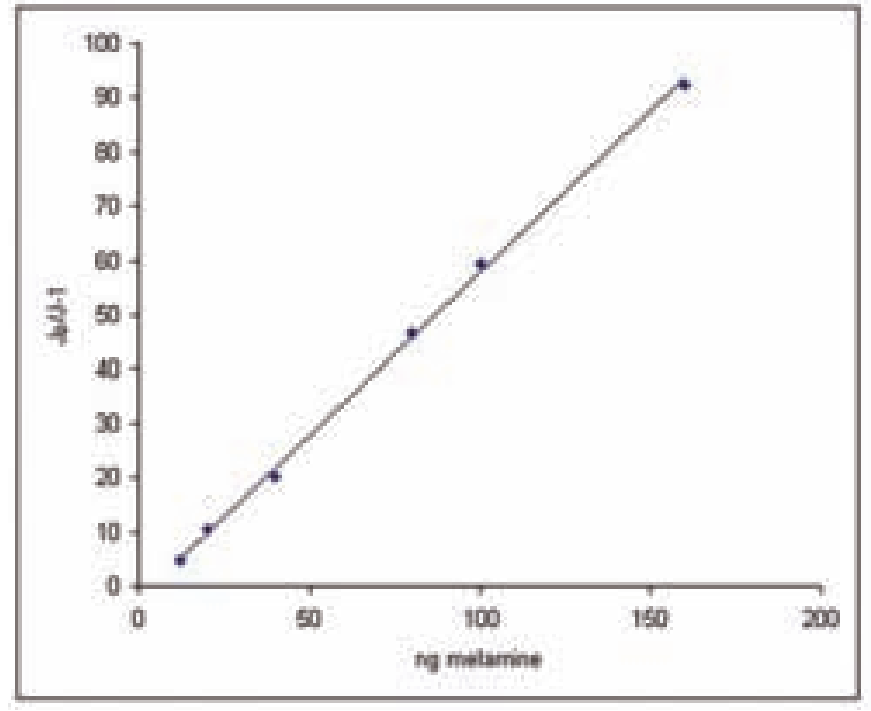

Fig. 3.5-6: shows the calibration curve of melamine spiked milk, stained with starch reagent and measured in the wavelength range from 490 to $610 \mathrm{~nm}$. Compared were the reflected light intensity (J) and the reflected light intensity of a clean plate surface $\left(J_{0}\right)$ 